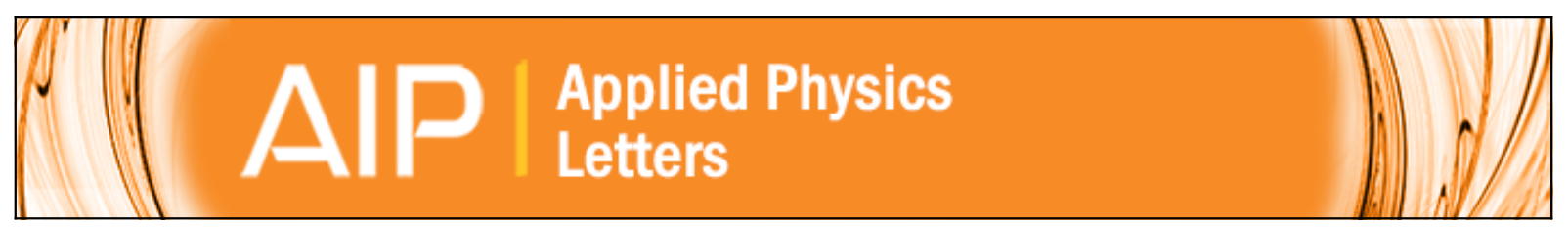

\title{
High temperature study of flexible silicon-on-insulator fin field-effect transistors
}

Amer Diab, Galo A. Torres Sevilla, Mohamed T. Ghoneim, and Muhammad M. Hussain

Citation: Applied Physics Letters 105, 133509 (2014); doi: 10.1063/1.4897148

View online: http://dx.doi.org/10.1063/1.4897148

View Table of Contents: http://scitation.aip.org/content/aip/journal/apl/105/13?ver=pdfcov

Published by the AIP Publishing

\section{Articles you may be interested in}

Hot carrier effect on gate-induced drain leakage current in high-k/metal gate n-channel metal-oxidesemiconductor field-effect transistors

Appl. Phys. Lett. 99, 012106 (2011); 10.1063/1.3608241

Modeling of threshold voltage, mobility, drain current and subthreshold leakage current in virgin and irradiated silicon-on-insulator fin-shaped field effect transistor device

J. Appl. Phys. 109, 084504 (2011); 10.1063/1.3553836

Observation of leakage sites in a hafnium silicon oxynitride gate dielectric of a metal-oxide-semiconductor fieldeffect transistor device by electron-beam-induced current Appl. Phys. Lett. 89, 222104 (2006); 10.1063/1.2392988

Electrical effects of a single stacking fault on fully depleted thin-film silicon-on-insulator P-channel metal-oxide-semiconductor field-effect transistors J. Appl. Phys. 91, 420 (2002); 10.1063/1.1417995

Unique method to electrically characterize a single stacking fault in silicon-on-insulator metal-oxide-semiconductor field-effect transistors

Appl. Phys. Lett. 77, 4034 (2000); 10.1063/1.1331641

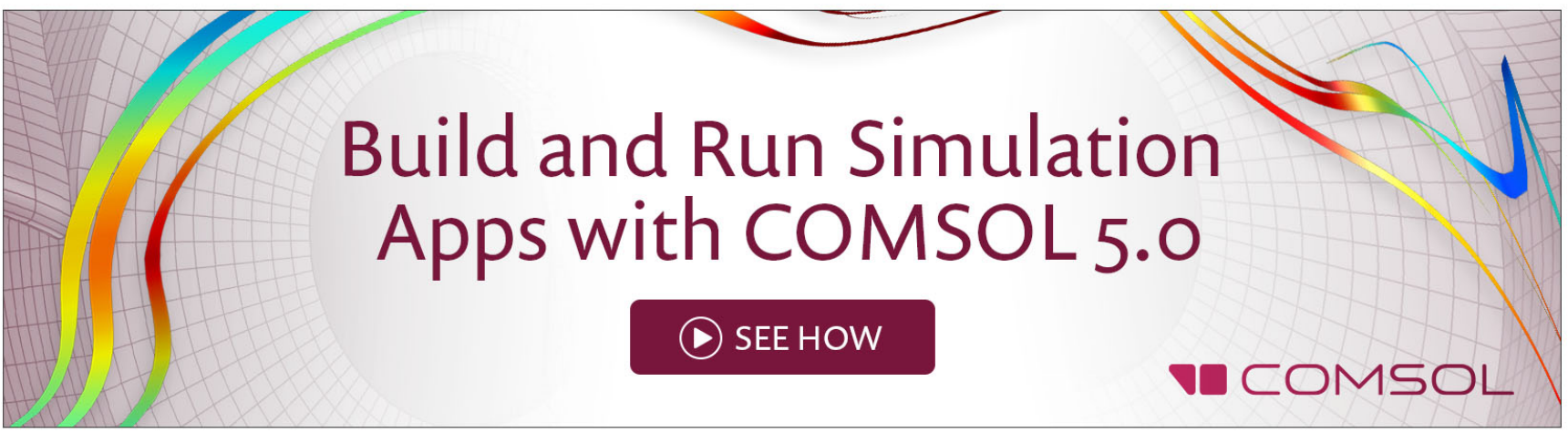




\title{
High temperature study of flexible silicon-on-insulator fin field-effect transistors
}

\author{
Amer Diab, Galo A. Torres Sevilla, Mohamed T. Ghoneim, and Muhammad M. Hussain ${ }^{\text {a) }}$ \\ Integrated Nanotechnology Lab, Electrical Engineering, Computer Electrical Mathematical Science and \\ Engineering Division, King Abdullah University of Science and Technology, Thuwal 23955-6900, \\ Saudi Arabia
}

(Received 28 May 2014; accepted 22 September 2014; published online 1 October 2014)

\begin{abstract}
We report high temperature electrical transport characteristics of a flexible version of the semiconductor industry's most advanced architecture: fin field-effect transistor on silicon-on-insulator with sub- $20 \mathrm{~nm}$ fins and high- $\kappa /$ metal gate stacks. Characterization from room to high temperature $\left(150^{\circ} \mathrm{C}\right)$ was completed to determine temperature dependence of drain current $\left(\mathrm{I}_{\mathrm{ds}}\right)$, gate leakage current $\left(\mathrm{I}_{\mathrm{gs}}\right)$, transconductance $\left(\mathrm{g}_{\mathrm{m}}\right)$, and extracted low-field mobility $\left(\mu_{0}\right)$. Mobility degradation with temperature is mainly caused by phonon scattering. The other device characteristics show insignificant difference at high temperature which proves the suitability of inorganic flexible electronics with advanced device architecture. (C) 2014 AIP Publishing LLC.
\end{abstract}

[http://dx.doi.org/10.1063/1.4897148]

Flexible electronics are one of the most popular rising branches and emerging field of traditional electronics towards future electronics. Flexible devices have the potential for a paradigm shift from today's rigid and brittle silicon (Si)/silicon-on-insulator (SOI) based electronics, to flexible displays, sensors, smart phones, and advanced healthcare devices. ${ }^{1}$ Several approaches have been investigated to make high performance flexible electronics. These approaches can be divided into three main categories: (i) using naturally flexible organic materials; (ii) inorganic substrate transfer method; and (iii) pseudo-complementary metal oxide semiconductor (CMOS) compatible techniques. ${ }^{2}$ Low cost, excellent flexibility and other advantages can be obtained with the first method by fabricating organic electronic devices on flexible polymeric substrates. Nevertheless, the challenges of its expansion are numerous including inherently low electron mobility compared to the most traditional inorganic semiconductor: mono-crystalline silicon, low integration density, and thermal instability. ${ }^{3}$ The second method that has been used consists of peeling off nano-ribbons or partially processed devices from various inorganic substrates followed by transfer onto flexible polymeric substrates (plastic, aluminum foil, etc.). ${ }^{4}$ It is worthy to note that this method is still rising and is mostly focused on emerging electronics applications. The last approach utilizes some of the semiconductor industry's most expensive and abrasive fabrication processes such as anodic etching, epitaxy, high energy implantation, and abrasive back grinding. ${ }^{5}$ Although competitive and exciting results have been reported using such methods, often they are expensive, unorthodox, resulting films are opaque and suffer from limited bendability. Therefore, as a complementary approach, in the recent past we showed an innovative and a fully CMOS compatible low-cost process to transform traditional inorganic devices into flexiblestretchable-transparent ones while retaining high

\footnotetext{
${ }^{\text {a) }}$ Author to whom correspondence should be addressed. Electronic mail: MuhammadMustafa.Hussain@kaust.edu.sa
}

performance and integration density. ${ }^{6}$ Flexible inorganic electronics can be revolutionary as they have inherent high performance, energy efficiency, ultra-large-scale-integration (ULSI) density, and low-cost. Additionally, their thermal stability enables them to be used for high temperature environments. As an example, such flexible inorganic devices can be integrated for electronic systems to be placed in locations like industrial pipelines, where the surface is non-planar and the environment tends to be harsh. Hence, the aim of this work is to investigate a flexible version of the silicon-on-insulator based fin field-effect transistors (FinFETs) with sub20 fins, high- $\kappa /$ metal gate at high temperature. High temperature measurements provide insightful information about transport parameters, which is not available from room temperature experiments. In this paper, temperature variation of the basic electrical parameters such as leakage current $\left(\mathrm{I}_{\mathrm{gs}}\right)$, Gate-Induced Drain Leakage (GIDL), and low-field mobility $\left(\mu_{0}\right)$ is reported and discussed.

The FinFETs are fabricated using monitor grade $8 \mathrm{in}$. SOI wafers following a state-of-the-art CMOS compatible gate-first flow. After patterning the fins (down to sub-20 nm width) using deep ultraviolet lithography (DUV) followed by extreme resist trimming, we formed $10-20 \mathrm{~nm}$ TiN/2-4 nm $\mathrm{HfO}_{2}$ gate stacks $\left(250 \mathrm{~nm}-1 \mu \mathrm{m}\right.$ gate length $\left.\mathrm{L}_{\mathrm{g}}\right)$. Source and drain were formed using ion implantation followed by $\mathrm{NiSi}$ and activation anneal at $1000^{\circ} \mathrm{C}$ for $10 \mathrm{~s}$. Finally, the devices had FGA $\left(\mathrm{N}_{2} / \mathrm{H}_{2}\right.$ at $\left.420^{\circ} \mathrm{C}\right)$. Process details can be found in Figure 1 and in our previous publications. ${ }^{7}$ Our normal trench-protect-release-reuse flexing process results in trenches in the peeled silicon fabric which causes faster heat dissipation. To avoid this, we have performed our process from the backside of the wafer so that the peeled silicon fabric is a continuous film without any trench formation substrate loss. In order to process each die separately, the wafer was diced into $7.5 \mathrm{~cm}^{2}$ pieces. Each individual die was spin-coated with photoresist (PR) to protect the devices. Then, each die was back etched using our process in order to reduce the bulk thickness. Careful monitoring is performed 


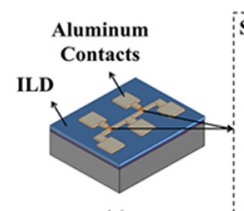

(a)
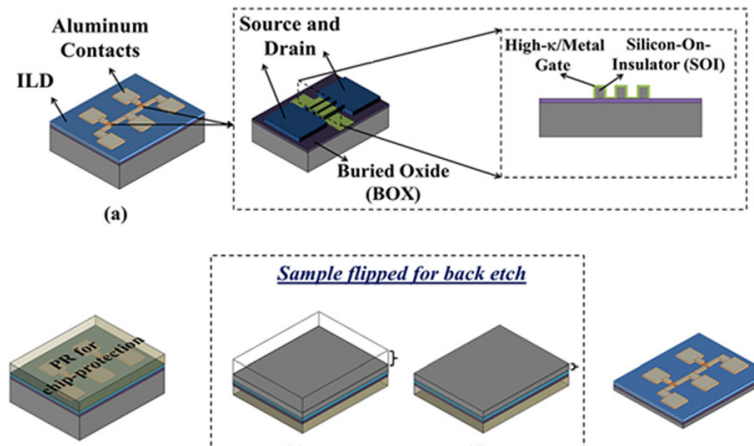

(b)

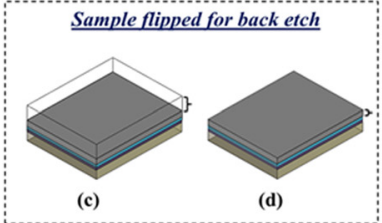

(c)

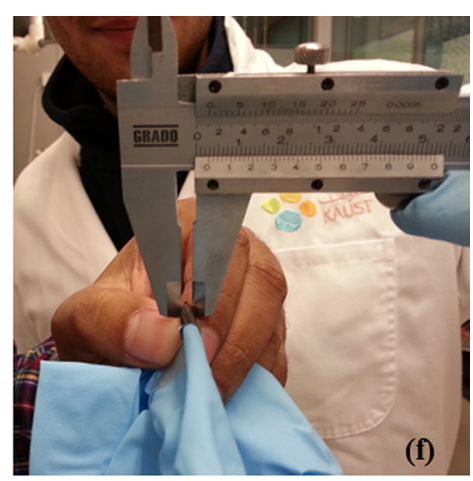

FIG. 1. Fabrication process flow: (a) fabricated FinFET devices on standard $90 \mathrm{~nm}$ SOI with $150 \mathrm{~nm}$ buried oxide (BOX); (b) PR coating for device protection during etch back process; (c) FinFET die etched back using back grinding technique; (d) FinFET devices on flexible silicon substrate $(50 \mu \mathrm{m}$ thick); (e) PR removal and final device testing and (f) digital photo of flexed FinFET with bending radius of $0.5 \mathrm{~mm}$. during the process to make sure that the bulk wafer is not completely removed in order to achieve mechanical support and flexibility at the same time. To achieve this, we divided the whole process into two parts, substrate thinning and thickness measurements. Once the bulk achieves a thickness of $50 \mu \mathrm{m}$ (flexibility is controlled by the final bulk thickness), the devices are bendable enough $(0.5 \mathrm{~mm}$ bending radius achieved) without the need for any transfer process due to the support provided by the remaining substrate. Finally, the PR was removed from the top and the devices were tested at different temperatures.

To study the behavior of the FinFETs at high temperature, our current-voltage measurements (in linear and saturation region) were performed using a Keithley SCS-4200 Semiconductor analyzer on a Cascade probe bench and the temperature was controlled with an ERS AirCool-Chuck System SP72 in a range between $25^{\circ} \mathrm{C}$ and $150^{\circ} \mathrm{C}$ with a $25^{\circ} \mathrm{C}$ step variation. Released and unreleased P-MOS FinFET devices with gate width $\mathrm{W}_{\mathrm{g}}=3.6 \mu \mathrm{m}, \mathrm{L}_{\mathrm{g}}=1 \mu \mathrm{m}$, and $\mathrm{L}_{\mathrm{g}}=250 \mathrm{~nm}$ and 20 channels were tested in parallel. We focused on saturation region (at drain voltage $\mathrm{V}_{\mathrm{ds}}=-1 \mathrm{~V}$ ) for the lowest $\left(25^{\circ} \mathrm{C}\right)$ and highest $\left(150^{\circ} \mathrm{C}\right)$ temperature curves to comprehend a full analysis. It is important to note that the same behavior was obtained in the linear region (at $\mathrm{V}_{\mathrm{ds}}=-0.05 \mathrm{~V}$, not shown in this work).

The saturated drain current $\left(\mathrm{I}_{\mathrm{ds}}\right)$ of "long" $\left(\mathrm{L}_{\mathrm{g}}=1 \mu \mathrm{m}\right)$ and "short" $\left(\mathrm{L}_{\mathrm{g}}=250 \mathrm{~nm}\right)$ released and unreleased FinFETs as a function of the gate-voltage $\left(\mathrm{V}_{\mathrm{gs}}\right)$ on linear scale is shown in Figure 2(a) for the lowest and the highest temperatures. The decrease of threshold voltage $\left(\mathrm{V}_{\text {th }}\right)$ with temperature tends to increase drain current, while the reduction of mobility due to increase of phonon scattering with temperature tends to decrease drain current, same as in a conventional MOSFET. 8 The compensation of these opposing effects at $\mathrm{V}_{\mathrm{gs}}=-0.8 \mathrm{~V}$ and at $\mathrm{V}_{\mathrm{gs}}=-0.9 \mathrm{~V}$ for long and short devices, respectively, leads to unique points in the characteristics with zero temperature coefficient (ZTC). Inset of Figure 2(a) shows the output characteristics $\left(\mathrm{I}_{\mathrm{ds}}-\mathrm{V}_{\mathrm{ds}}\right)$ of long and short FinFETs at $25^{\circ} \mathrm{C}$ and at $150{ }^{\circ} \mathrm{C}$. These curves clearly show that the drive current of the FinFETs decreases with temperature as expected without any significant degradation after release. In Figure 2(b), we traced the saturated drain current for the released and unreleased FinFETs as a function of $\mathrm{V}_{\mathrm{gs}}$ on the semi-logarithmic scale. The subthreshold swing (SS) increases in all devices as temperature increases. ${ }^{9}$ In addition, we plotted the $\mathrm{I}_{\mathrm{gs}}$ as a function of $\mathrm{V}_{\mathrm{gs}}$ (inset of Figure 2(b)) where the gate current increases with temperature and the variation after release sustains the $\mathrm{nA}$ values range. Figure 2 confirms an insignificant variation of drain current, gate-current, threshold voltage, and the subthreshold swing at high and low temperatures. Furthermore, Table I shows a comparison between the extracted parameters of the best benchmark rigid FinFET (from Intel) and our flexible FinFET (this work). ${ }^{10}$ Following, we focus on the behavior of leakage currents and mobility with temperature for rigid and flexible FinFETs.

The variation with temperature of the gate current $\left(\mathrm{I}_{\mathrm{gS}}\right)$ on semi-logarithmic scale extracted for $V_{\mathrm{gs}}=1 \mathrm{~V}$ and $\mathrm{V}_{\mathrm{ds}}=-1 \mathrm{~V}$ (i.e., worst-case bias) is shown in Figure 3(a) for long and short FinFETs. The gate leakage current values are low due to the high- $\kappa$ dielectric and do not exhibit strong temperature dependence for both released and unreleased devices. A small increase of $\mathrm{I}_{\mathrm{gs}}$ at $150{ }^{\circ} \mathrm{C}$ is obtained for released FinFETs, 25\% and $45 \%$ for short and long devices, respectively. At high drain voltage, gate leakage becomes negligible as compared to drain leakage. Gate induced drain lowering (GIDL) effect manifests itself as a factor to increase $I_{d s}$ when a positive $V_{g s}$ is applied to the gate of a p-channel
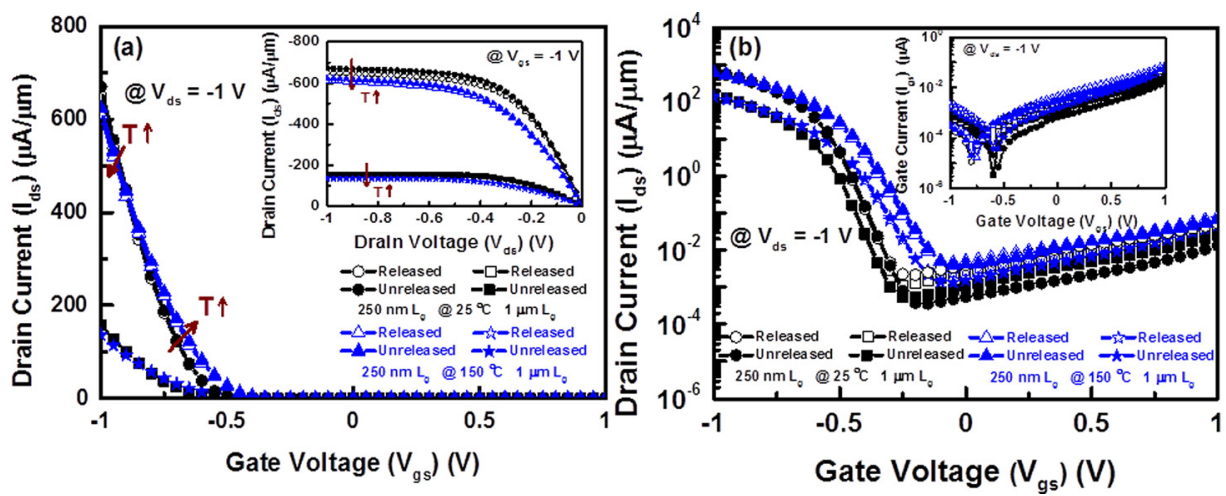

FIG. 2. (a) Unreleased and released FinFET transfer plots $\left(\mathrm{I}_{\mathrm{ds}}-\mathrm{V}_{\mathrm{gs}}\right)$ on linear scale for $25^{\circ} \mathrm{C}$ and $150^{\circ} \mathrm{C}$. Inset: output plots $\left(\mathrm{I}_{\mathrm{ds}}-\mathrm{V}_{\mathrm{ds}}\right)$ for same devices and temperature values. Variation with temperature shows no device performance degradation. (b) Unreleased and released FinFET transfer plots $\left(\mathrm{I}_{\mathrm{ds}}-\mathrm{V}_{\mathrm{gs}}\right)$ on semi-logarithmic scale for $25^{\circ} \mathrm{C}$ and $150^{\circ} \mathrm{C} . \mathrm{V}_{\text {th }}$ decreases and SS increases with increasing temperature. Inset: $I_{g s}$ versus $V_{g s}$ curves for same devices and temperature values showing non-degraded gate leakage values. 
TABLE I. Comparison of extracted parameters.

\begin{tabular}{lccccc}
\hline \hline & $L_{g}(\mathrm{~nm})$ & $I_{\text {on }}(\mathrm{mA} / \mu \mathrm{m})$ & $I_{\text {off }}(\mathrm{nA} / \mu \mathrm{m})$ & $S S(\mathrm{mV} / \mathrm{dec})$ & $\mu_{e f}\left(\mathrm{~cm}^{2} / \mathrm{V} \mathrm{s}\right)$ \\
\hline Intel Tri-gate FET (rigid) & 40 & 1.1 & 100 & 90 & 200 \\
This work DG FinFET (flexible) & 250 & 0.65 & 4 & 63 & 103 \\
\hline \hline
\end{tabular}

device. In general, the GIDL current is caused by band-toband tunneling (BBT) or band-to-defect tunneling (BDT) in the gate and drain overlap regions. ${ }^{11}$ The variation of the GIDL as a function of the temperature is shown in Figure 3(b) for the released and unreleased FinFETs. The increase in GIDL at the highest temperature, as compared to the lowest temperature, is below one order of magnitude. This weak temperature dependence suggests the band-to-band tunneling as the dominant mechanism at the overlap gate-drain region. ${ }^{12,13}$ The released FinFETs characteristics in Figure 3 do not vary considerably compared to the unreleased ones, thus proving our flexible fabrication process. It is important to mention that for the unreleased $250 \mathrm{~nm} \mathrm{~L} \mathrm{~L}_{\mathrm{g}}$ FinFET and specifically for the $25^{\circ} \mathrm{C}$ and $50^{\circ} \mathrm{C}$ temperatures, the reason for very low $\mathrm{I}_{\mathrm{gs}}$ and GIDL at $\mathrm{V}_{\mathrm{gs}}=1 \mathrm{~V}$ could come from the measurement setup (contact resistance).

The transconductance curves versus $\mathrm{V}_{\mathrm{gs}}$ are presented in Figure 4 for the long and short FinFETs at $25^{\circ} \mathrm{C}$ and $150^{\circ} \mathrm{C}$. The released and unreleased $\mathrm{g}_{\mathrm{m}}$ curves overlap, which confirms that our devices maintain almost the same performance after the extensive fabrication process. The reduction of the transconductance peak in Figure 4 as a function of the temperature is explained by the mobility lowering due to increased phonon scattering at elevated temperatures. ${ }^{8,9}$ Further, to confirm our results with a quantitative analysis, the extracted $\mu_{0}$ of the FinFETs is shown in Figure 5. The low-field mobility
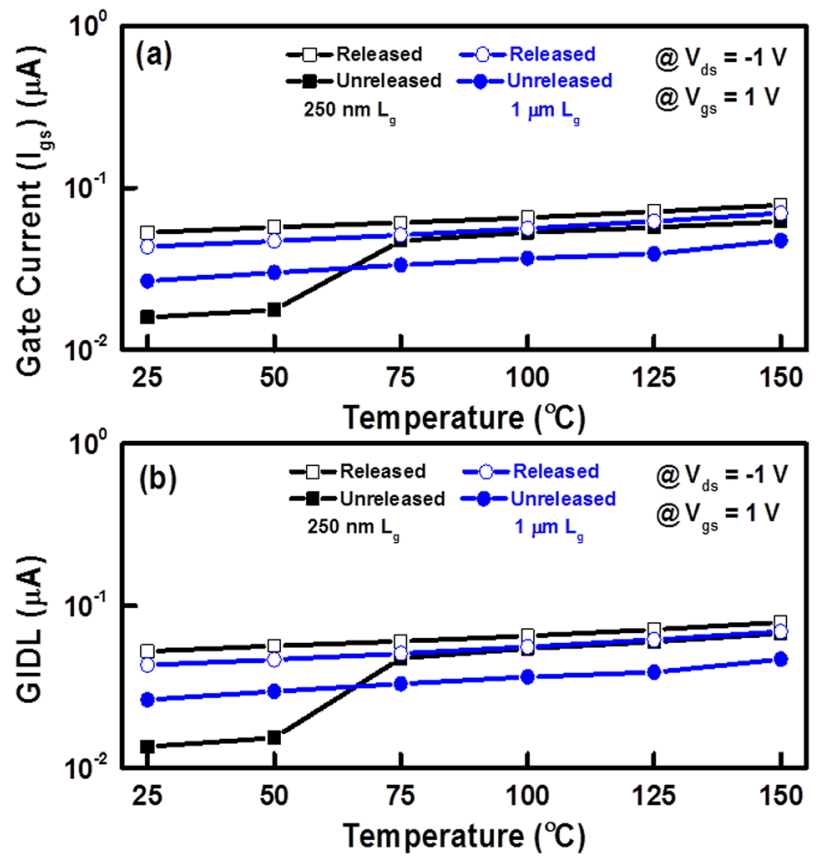

FIG. 3. Unreleased and released FinFET (a) gate-leakage current curves versus temperature and (b) GIDL versus temperature. Extracted values at $\mathrm{V}_{\mathrm{gs}}=1 \mathrm{~V}$ and curves are plotted on semi-logarithmic scale. A small increase of gate leakage and GIDL with increasing temperature is obtained. Band-toband tunneling is the dominant mechanism at the overlap gate-drain region. is extracted in linear regime $\left(\mathrm{V}_{\mathrm{ds}}=-0.05 \mathrm{~V}\right)$ using the $\mathrm{Y}=\mathrm{I}_{\mathrm{ds}} /\left(\mathrm{g}_{\mathrm{m}}\right)^{1 / 2}$ function method. ${ }^{14}$ The mobility curves decrease with temperature and no degradation of the extracted values after release is obtained. Since the starting SOI substrates are partially depleted (commercially they are sold as fully depleted), in these FinFETs, mobility is limited mainly by phonon scattering $\left(\mu \propto \mathrm{T}^{-\mathrm{n}}\right)$, which explains the decrease of mobility with temperature. ${ }^{15}$ In our case $\mathrm{n} \approx 1.7$ which shows that our flexing process does not generate any defects and preserves the good quality of the interface.

In summary, we have studied a flexible version of the industry's most advanced architecture, SOI FinFET with sub-20 nm fins, high- $\kappa /$ metal gate stacks, with extended electrical characterization study at room and high temperature to understand its transport phenomena. The measurements $\left(\mathrm{I}_{\mathrm{ds}^{-}}{ }^{-}\right.$ $\mathrm{V}_{\mathrm{gs}}, \mathrm{I}_{\mathrm{ds}}-\mathrm{V}_{\mathrm{ds}}, \mathrm{I}_{\mathrm{gs}}-\mathrm{V}_{\mathrm{gs}}$, and $\left.\mathrm{g}_{\mathrm{m}}-\mathrm{V}_{\mathrm{gs}}\right)$ at high temperature of high-performance flexible electronics are reported. As

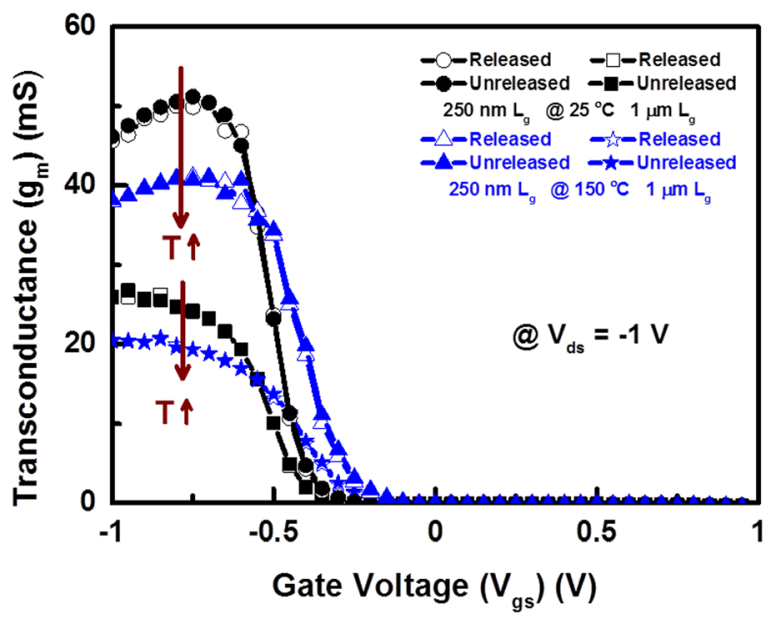

FIG. 4. Transconductance curves versus gate voltage for unreleased and released FinFET at $25^{\circ} \mathrm{C}$ and $150^{\circ} \mathrm{C}$. The $g_{m}$ peak decreases with increasing temperature.

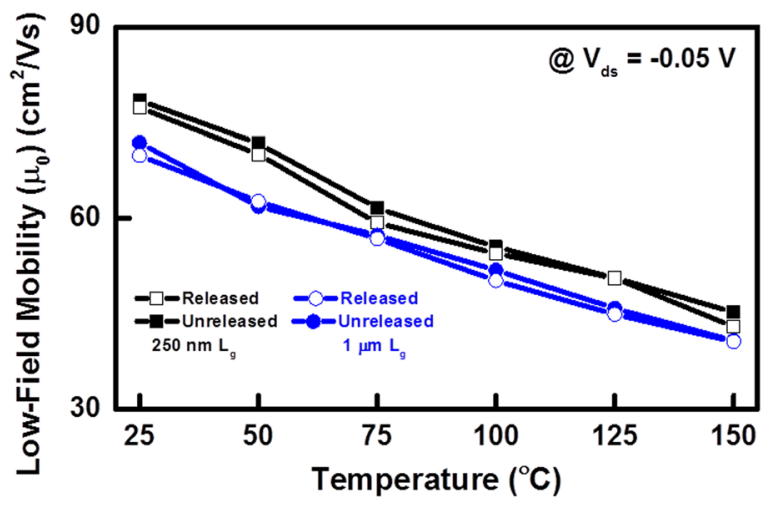

FIG. 5. Low-field mobility curves (extracted at $\mathrm{V}_{\mathrm{ds}}=-0.05 \mathrm{~V}$ from the Y-function method) versus temperature for unreleased and released FinFET. Mobility decreases with increasing temperature, caused by phonon scattering. 
theoretically expected and for both released and unreleased FinFETs, the gate leakage current and the GIDL increases with increasing temperature whereas the transconductance peak decreases with temperature. The extracted low-field mobility curves decrease with increasing temperature where the phonon scattering mechanism dominates. The performance variation with temperature confirms the efficiency and the stability of our devices after release. These results clearly show that flexible FinFET devices can be used for a wide range of complex electronic devices.

We thank KAUST OCRF Competitive Research Grant (CRG) CRG-1-2012-HUS-008 for supporting this research. We also thank Mrs. Kelly Rader for proof reading the manuscript.

${ }^{1}$ J. A. Rogers, M. G. Lagally, and R. G. Nuzzo, Nature 477(7362), 45 (2011).

${ }^{2}$ Y. Xia, V. Kalihari, C. Daniel Frisbie, N. K. Oh, and J. A. Rogers, Appl. Phys. Lett. 90(16), 162106 (2007); P. Lin and F. Yan, Adv. Mater. 24(1), 34 (2012); J. N. Burghartz, W. Appel, H. D. Rempp, and M. Zimmermann, IEEE Trans. Electron Devices 56(2), 321 (2009); G. A. Sevilla, J. P. Rojas, H. M. Fahad, A. M. Hussain, R. Ghanem, C. E. Smith, and M. M. Hussain, Adv. Mater. 26(18), 2794 (2014).

${ }^{3}$ J. Sun, B. Zhang, and H. E. Katz, Adv. Funct. Mater. 21(1), 29 (2011); J. N. Tiwari, J. Singh Meena, C.-S. Wu, R. N. Tiwari, M.-C. Chu, F.-C. Chang, and F.-H. Ko, ChemSusChem 3(9), 1051 (2010); A. Bag, M. K. Hota, S. Mallik, and C. K. Maiti, Semicond. Sci. Technol. 28(5), 055002 (2013).

${ }^{4}$ Y. Lee, L. Handong, and S. J. Fonash, IEEE Electron Device Lett. 24(1), 19 (2003); E. Menard, K. J. Lee, D.-Y. Khang, R. G.
Nuzzo, and J. A. Rogers, Appl. Phys. Lett. 84(26), 5398 (2004); E. Menard, R. G. Nuzzo, and J. A. Rogers, ibid. 86(9), 093507 (2005); Z.-T. Zhu, E. Menard, K. Hurley, R. G. Nuzzo, and J. A. Rogers, ibid. 86(13), 133507 (2005); S. Mack, M. A. Meitl, A. J. Baca, Z.-T. Zhu, and J. A. Rogers, ibid. 88(21), 213101 (2006); S. A. Stauth and B. A. Parviz, Proc. Natl. Acad. Sci. 103(38), 13922 (2006); H.-C. Yuan, J. Shin, G. Qin, L. Sun, P. Bhattacharya, M. G. Lagally, G. K. Celler, and Z. Ma, Appl. Phys. Lett. 94(1), 013102 (2009).

${ }^{5}$ D. Shahrjerdi and S. W. Bedell, Nano Lett. 13(1), 315 (2013).

${ }^{6}$ J. P. Rojas, G. T. Sevilla, and M. M. Hussain, Appl. Phys. Lett. 102(6), 064102 (2013).

${ }^{7}$ M. M. Hussain, C. E. Smith, H. Rusty Harris, C. D. Young, T. HsingHuang, and R. Jammy, IEEE Trans. Electron Devices 57(3), 626 (2010).

${ }^{8}$ D. S. Jeon and D. E. Burk, IEEE Trans. Electron Devices 36(8), 1456 (1989).

${ }^{9}$ J. Colinge, L. Floyd, A. J. Quinn, G. Redmond, J. C. Alderman, W. Xiong, C. R. Cleavelin, T. Schulz, K. Schruefer, G. Knoblinger, and P. Patruno, IEEE Electron Device Lett. 27(3), 172 (2006).

${ }^{10}$ J. Kavalieros, B. Doyle, S. Datta, G. Dewey, M. Doczy, B. Jin, D. Lionberger, M. Metz, W. Rachmady, M. Radosavljevic, U. Shah, N. Zelick, and R. Chau, Int. Symp. VLSI Technol. 2006, 50-51.

${ }^{11}$ D. Rideau, A. Dray, F. Gilibert, F. Agut, L. Giguerre, G. Gouget, M. Minondo, and A. Juge, in 2004 Int. Conf. on Microelectron. Test Struct. 2004, 149-154.

${ }^{12}$ M. Lemme, T. Mollenhauer, W. Henschel, T. Wahlbrink, H. Gottlob, J. Efavi, M. Baus, O. Winkler, B. Spangenberg, and H. Kurz, Proc. Eur. Solid-State Device Res. 2003, 123-126.

${ }^{13}$ T. Hoffmann, G. Doornbos, I. Ferain, N. Collaert, P. Zimmerman, M. Goodwin, R. Rooyackers, A. Kottantharayil, Y. Yim, A. Dixit, K. De Meyer, M. Jurczak, and S. Biesemans, IEEE Int. Electron Devices Meet. 2005, 725-728.

${ }^{14}$ G. Ghibaudo, Electron. Lett. 24(9), 543 (1988).

${ }^{15}$ S. M. Sze, Physics of Semiconductor Devices, 2nd ed. (Wiley Press, New York, 1981). 